\title{
Allelic variation in the vitamin $D$ receptor influences susceptibility to IDDM in Indian Asians
}

\author{
M . F. M cD ermott ${ }^{1}$, A . R amachandran ${ }^{3}$, B .W. 0 gunkolade $^{1}$, E . A ganna ${ }^{1}$, D.C urtis ${ }^{2}$, B .J . B oucher ${ }^{1}$, C . Snehalatha ${ }^{3}$, \\ G . A . H itman ${ }^{1}$ \\ ${ }^{1}$ Medical Unit, St. Bartholomew's and The Royal London School of Medicine, London, UK \\ ${ }^{2}$ Department of Psychiatry, St. Bartholomew's and The Royal London School of Medicine, London, UK \\ ${ }^{3}$ Diabetes Research Centre, Madras, India
}

Summary Vitamin D has important immunomodulatory properties and prevents development of diabetes mellitus in an animal model of insulin-dependent diabetes (IDDM). We have studied the vitamin D receptor locus as a candidate for genetic susceptibility to IDDM in Southern Indian families. We found evidence for an association of one particular vitamin D receptor allele with IDDM susceptibility in this community. Ninety-three South Indian families consisting of available parents and an affected offspring were genotyped for three vitamin $\mathrm{D}$ receptor polymorphisms using the restriction enzymes Taql, A pal and $\mathrm{Bsml}$ as well as an adjacent microsatellite located to 12q14 (D12S85). Transmission disequilibrium testing analysis was used to assess preferential transmission of polymorphic markers and haplotypes with IDDM. There was significant excess transmission of vitamin D receptor alleles containing the Bsml restriction site to affected offspring in these families $(p=0.016)$. No association was found between D12S85 and IDDM. This study suggests that a polymorphism within or close to the vitamin D receptor gene may modify susceptibility to IDDM in this ethnic group. [Diabetologia (1997) 40: 971-975]

Keywords Vitamin D receptor, genotype, insulin-dependent diabetes, genetic susceptibility, South India.
Insulin-dependent diabetes mellitus (IDDM) is a multifactorial disease with a strong genetic component [1]. The main genetic contribution to IDDM susceptibility lies in the major histocompatibility complex (MHC) on the short arm of chromosome 6 and several non-MHC chromosomal regions are also involved [2]. Various initial approaches have been used to identify IDDM susceptibility regions including case-control studies of candidate genes [HLA,

Received: 15 January 1997 and in revised form: 8 May 1997

Corresponding author: Professor G. A.Hitman, Medical Unit, The Royal London Hospital, The Royal Hospitals N.H.S. Trust, Whitechapel, London E1 BB, UK

A bbreviations: IDDM, Insulin-dependent (Type 1) diabetes mellitus; VDR, Vitamin D receptor; RFLP, restriction fragment length polymorphism; TDT, transmission disequilibrium test; MHC, major histocompatibility complex; ETDT, extended transmission disequilibrium test; mRNA, messenger RNA; ILIR1, interleukin-1 receptor type 1. insulin gene regulatory region, interleukin-1 receptor type 1 gene (ILIR1)] [3-6], combined linkage and association-based studies of candidate genes (CTLA4 a receptor on activated T cells) [7], and systematic total genome searches in addition to individual chromosomal regions [8-16].

There are clear differences in immunogenetic predisposition to IDDM between countries and these seem to vary with disease incidence [1]. IDDM in Southern India has a similar incidence (10.4/100000 cases per year) to Asian children in the UK and white children of European extraction [17, 18]. While an MHC component to susceptibility is detectable [19, $20]$ in IDDM in Southern India no association with either the insulin gene [20] or interleukin-1 receptor type 1 [6] has been found using a case-control design. This finding suggests possible differences in the nonMHC IDDM component in this ethnic group compared to whites of European extraction. In the latter populations an association with the insulin gene has been universally reported $[4,5,21]$, and an ILIR1 
association with IDDM has been described in some studies of northern Europeans [6, 22].

IDDM develops as a result of autoimmune destruction of the insulin producing pancreatic beta cells; vitamin D has important immunomodulatory properties and influences insulin secretion [23]. The active form of vitamin D (1,25 dihydroxyvitamin D3) inhibits $\mathrm{T}$ cell proliferation and suppresses both tumour necrosis factor $\alpha$ (TNF $\alpha)$ and interleukin-1 production [24]. Furthermore, in the NOD mouse (an excellent animal model of IDDM) vitamin D3 administration prevents the development of IDDM as well as the associated autoimmune insulitis [25]. In a recent study in Bangladeshi subjects living in east London, vitamin $\mathrm{D}$ levels were found to be reduced in those most at risk for non-insulin-dependent diabetes [26]. Therefore, we have studied the vitamin $\mathrm{D}$ receptor (VDR) locus on chromosome $12 \mathrm{q}$ as a candidate gene for IDDM susceptibility in Southern Indian subjects using the transmission disequilibrium test (TDT) $[27,28]$ in family trios consisting of parents and affected offspring.

\section{Subjects, materials and methods}

IDDM families: A total of 93 Southern Indian families were recruited from patients attending the MV Hospital for Diabetes, Madras, India. All affected subjects were ketosis prone and had acute onset of disease which required immediate treatment with insulin. Cases of fibrocalculous pancreatic diabetes were excluded by radiology, ultrasonography and on clinical grounds. The mean age of onset in IDDM probands was 11.1 years ( \pm 6.6 years; range $1-29$ years), the male to female sex ratio was 0.45 , mean body mass index at time of venesection was $18.2 \pm 5.03$ and $54 \%$ of 48 probands tested had antibodies to glutamic acid decarboxylase (GAD65; unpublished data). Blood samples were taken from 93 probands; in addition, both parents were studied in 83 of these families, and from 1 parent in the remaining 10 families. Overall NIDDM was present in $16 \%$ of parents and IDDM was diagnosed in 2 of the fathers. Informed consent was obtained from all families prior to blood sampling in Madras.

Experimental methods. DNA was extracted from whole blood (Puregene kits; Centra Systems Inc., Minneapolis, USA). All family members were initially genotyped for three restriction fragment length polymorphic (RFLP) sites (B sml and A pal in successive introns between exons 7 and 9 of the VDR gene, and Taql within the 9th exon) [29]. Genotypes were determined by two separate polymerase chain (PCR) amplifications followed by restriction endonuclease digestion of the products (A pal and Taql for the first PCR; B sml for the second). Fragments were separated on $1.5 \%$ agarose gels (in the case of $\mathrm{Bsml}$ ), and $3 \%$ for A pal and Taql; the gels were visualised by ethidium bromide ultraviolet illumination. Genotypes were designated conventionally by a lower case letter for the presence of a cut site and a capital letter for the absence, e.g. the ' $b$ ' allele designates the presence of a B sml site, and, likewise, 'B' the absence. The genotypes therefore are bb, BB (homozygous for the presence and absence of the cut site respectively) and $\mathrm{Bb}$ (heterozygous). All samples were analysed at least twice to ensure the validity of genotyping, and all results assessed blindly by an independent investigator. A fluorescently labelled microsatellite (D12S85) located 2cM from the VDR was also used to genotype all members of these families. PCR primers were chosen from published sequences [30] and a touchdown technique was employed. Amplified fragments were separated by polyacrylamide gel electrophoresis on an ABI 373 DNA sequencer and fragments analysed using GENESCANNER software. There were at least 10 alleles of this marker in the families with a size range of 104-130 base pairs (bp) [30].

Statistical analysis. The transmission disequilibrium test (TDT) was used to detect preferential transmission of the RFLP alleles to affected subjects [27]. For each heterozygous parent, the probability of transmitting either allele to an affected offspring is equal unless the polymorphism is linked and associated with the disease, deviation of transmission probabilities from 50:50 therefore provides good evidence for association due to linkage disequilibrium. In addition, haplotypes were constructed where possible from combinations of two RFLPs and also from a combination of all three RFLPs; these haplotypes were then treated as "pseudo-alleles" and analysed using the extended transmission disequilibrium test (ETDT) which deals with multiallelic polymorphisms [27]. The ETDT provides an overall test of transmission distortion for a multiallelic polymorphism either by considering all heterozygous parental genotypes separately (genotype-wise analysis), or by combining information across genotypes to detect effects due to particular alleles (allele-wise analysis). Where overall tests were positive for a haplotype system individual haplotypes were assessed to see which one accounted for the overall effect. Genotype distributions between subgroups of patients of IDDM patients were compared using the chi-square test.

\section{Results}

Restriction fragment length polymorphism (RFLP) data were available for all three enzymes in all 93 families. Since TDTrelies on transmissions from heterozygous parents to affected offspring the numbers of informative families vary according to the enzyme used. ETDT analysis for individual RFLPs found that the " $b$ " allele of the Bsml RFLP was preferentially transmitted to affected offspring [53 of 84 times (53/ 84); $p=0.016$ ]; ETDT analysis for haplotypes based on two RFLPs also demonstrated significant preferential transmission of the 'bT' haplotype (41/59; $p=0.003$ ) (Table 1). There was further evidence for preferential transmission of the Bsml/A pal (allelewise $p=0.026$, genotype-wise; $p=0.080$ ) and $B$ sml / Taql haplotypes (allele-wise $p=0.011$, genotypewise; $p=0.036$ ) (this latter effect is due mainly to the significant transmission of ' $\mathrm{bT}$ '). The disease associated alleles and haplotypes were equally transmitted by fathers and mothers. There was weak evidence for an extended haplotype effect (i.e. all three RFLPs) (allele-wise $p=0.074$, genotype-wise; $p=0.047$ ). Table 2 shows that the 'bAT' haplotype was preferentially transmitted to affected offspring on 35 out of 54 occasions $(p=0.0295)$ (seven of the eight possible haplotypes were observed in these families). The bAT 
Table 1. Bsml/Taq1 vitamin D receptor haplotypes in 93 South Indian families

\begin{tabular}{lllll}
\hline & \multicolumn{4}{l}{ Haplotypes } \\
\cline { 2 - 5 } & $\mathrm{BT}$ & $\mathrm{bT}$ & $\mathrm{Bt}$ & $\mathrm{bt}$ \\
\hline Transmitted & 11 & 41 & 21 & 2 \\
Not transmitted & 27 & 18 & 29 & 1 \\
p values & 0.009 & 0.0028 & 0.26 & - \\
\hline
\end{tabular}

Chi-square for allele-wise TDT $=11.12$ (3 degrees freedom) $p=0.011$

Chi-square for genotype-wise TDT $=11.88$ ( 5 degrees freedom) $p=0.036$

Table 2. B SMI/A pal/Taql vitamin D receptor haplotypes and IDDM

\begin{tabular}{llllllll}
\hline & \multicolumn{9}{l}{ Haplotypes } & & & & \\
\cline { 2 - 8 } & BAT & Bat & bAT & bAt & baT & BaT & bat \\
\hline Transmitted & 13 & 23 & 35 & 1 & 34 & 2 & 5 \\
Non-transmitted & 29 & 25 & 19 & 2 & 28 & 2 & 8 \\
p values & 0.014 & 0.77 & 0.0295 & - & 0.446 & - & 0.405
\end{tabular}

Chi-square for allele-wise TDT $=11.47$ ( 6 degrees freedom) $p=0.0747$

Chi-square for genotype-wise TDT $=23.91$ (14 degrees freedom) $p=0.0470$

haplotype was the third most common haplotype found in the parents of the IDDM probands (frequency 0.22 compared to 0.26 for BAt and 0.25 for baT).

There was no evidence for preferential transmission of either Taql (allele-wise $p=0.33$ ) or A pal (allele-wise $p=0.46$ ) alleles, and no association between IDDM and A pal/Taql haplotypes was found (allelewise $p=0.17$ ). TDT analysis of D12S85 revealed no evidence of association between this marker and IDDM (allele-wise $p=0.13$ ).

Probands with an age of onset of IDDM of 15 years or below $(n=72)$ and those greater than 15 years $(n=21)$ were compared for genotype distribution of RFLPs; no differences were observed for Bsml $(p=0.87)$, Taql $(p=0.84)$ or A pal $(p=0.9)$. In the smaller number of probands tested for GAD65 antibodies $(n=48)$, no differences were observed according to the presence or absence of GAD65 antibodies (Bsml, $p=0.82 ;$ Taql , $p=0.96$ and A pal , $p=0.89$ ).

\section{Discussion}

The results of this study demonstrate preferential transmission of the " $b$ " allele of the Bsm1 RFLP to affected subjects. Extended haplotypes containing this allele, denoted bT and bAT, also demonstrate preferential transmission but we cannot determine whether this is due to a primary association between IDDM and these haplotypes, or whether the association is strictly with the " $b$ " allele of the Bsm1 RFLP itself.
The VDR locus has been extensively studied for association with susceptibility to osteoporosis, and the Bsm1 ' $\mathrm{B}$ ' allele has been associated with reduced bone mineral density in separate studies [31, 32]. However, these findings are not consistent, and several groups have failed to reproduce these initial observations [29, 33]; indeed at least one study has found the alternative "b" allele associated with particular subgroups of osteoporosis [34]. The 'bb' genotype has also been associated with primary hyperparathyroidism in Swedish patients [35]. Although the nucleotide sequence of the VDR gene has not been reported for the IDDM associated bAT haplotype, sequences from the two most common haplotypes in Caucasoids (Bat and baT) are available and only neutral coding region variants are described. Some polymorphic differences between the haplotypes were found in the 3' untranslated region between the baT and Bat haplotypes which were associated with reduced gene transcription $[31,36]$ and mRNA stability.

The VDR gene located on chromosome 12q12$12 q 14$ is not in a region linked to IDDM in a genome scan of European and North American Caucasoid affected sibling pairs [8]. This does not exclude VDR gene involvement in IDDM as true linkage is easily missed in complex diseases, and for particular candidate loci association-based approaches such as TDT may be more powerful than linkage. Hence both the insulin gene and CTLA4 gene have been implicated in IDDM primarily by association studies, despite weak evidence in favour of linkage to these genes [4, $5,7]$. Because linkage disequilibrium only occurs over very short genetic distances in out-bred populations, association studies are not suitable for studying random markers in a genome scan but are the method of choice for candidate gene study. The case-control design is prone to false positives if population stratification is present (i.e. cases and controls are sampled from genetically different sub-populations), so results obtained by this approach must always be regarded with caution. By contrast, transmission disequilibrium testing uses those alleles not transmitted by parents to affected offspring to form the control group; positive results thus obtained are therefore likely to be due to a true genetic association between marker and disease loci. Our results are formally significant and seem unlikely to have occurred by chance, especially given the biological plausibility of the candidate gene studied. D12S85 is $2 \mathrm{cM}$ from the VDR locus on $12 q 12-12 q 14$. Since no association was found between this latter marker and IDDM, it would indicate susceptibility is located close to the VDR locus, and that D12S85 is in linkage equilibrium with the studied polymorphisms of the VDR locus. Recently, a locus on 12q24 (NIDDM1) has been found to be linked to insulin secretion in NIDDM [37]; furthermore, this region also contains the 
MODY3 locus [38]. In maturity onset diabetes of the young, the MODY3 locus has recently been cloned and found to be due to a variant of hepatic nuclear factor-1 $\alpha$ [39]. The distance between 12q12-12q14 (VDR location) and 12q24 (NIDDM1/MODY3) rules out our observations in IDDM being explained by associations between IDDM and either the NIDDM1 or MODY3 gene.

The immunogenetic predisposition to IDDM in South India has differences from that observed in whites of European extraction. While we have previously described associations between IDDM and DQB1*0302 and DQB1*0201 in South Indian subjects there is a decreased frequency of heterozygotes for DQB1*0302/DQB1*0201 in this ethnic group compared to whites [19, 20 and unpublished data]. Furthermore, there are also differences at non MHCloci $[6,20]$. Nonetheless, this is typical IDDM on clinical grounds, as indicated by the clinical presentation, the high frequency of GAD65 antibody positivity and an incidence of IDDM similar to many European populations [18]. Though the numbers are small, the VDR genotype distribution in the probands was not different according to GAD65 antibody status or age of onset of IDDM. Therefore, the VDR gene association we describe in this ethnic group is unlikely to be explained by an atypical form of IDDM or insulin-treated NIDDM in the guise of IDDM.

In conclusion, this study suggests that a polymorphism within or close to the VDR gene may modify susceptibility to IDDM in subjects living in South India. Replication of this result is necessary in other samples, preferably drawn from the same ethnic group and by identification of the particular polymorphisms within or close to VDR which directly affect susceptibility to IDDM.

Acknowledgements. We are indebted to the late Professor Moopil Viswanathan (Madras) who helped plan this study. This study was supported, in part, by a grant from the British Diabetic Association.

\section{References}

1. Atkinson MA, Maclaren NK (1994) Mechanisms of disease: the pathogenesis of insulin-dependent diabetes mellitus. N Engl J Med 331: 1428-1436

2. Cordell HJ, Todd JA (1995) Multifactorial inheritance in type 1 diabetes. Trends Genet 11: 499-503

3. Nerup J, Platz P, Ortved-Anderson O, Christy M, Lynsgoe J, Poulsen JE (1974) HLA antigens and diabetes mellitus. Lancet 2 (7885): 864-866

4. Bell GI, Horita S, Karam JH (1984) A polymorphic marker near the human insulin gene is associated with insulin dependent diabetes mellitus. Diabetes 33: 176-183

5. Hitman GA, Tarn AC, Winter RM, et al. (1985) Type 1 (insulin-dependent) diabetes and a highly variable locus close to the insulin gene on chromosome 11. Diabetologia 28: 218-222
6. Metcalfe KA, Hitman GA, Pociot F, et al. (1996) An association between type 1 diabetes and the interleukin- 1 receptor type 1 gene. Hum Immunol 51: 41-48

7. Nistico L, Buzzetti R, Pritchard LE, et al. (1996) The CTLA-4 gene region of chromosome 2 q33 is linked to, and associated with, type 1 diabetes. Hum Mol Genet 5: 1075-1080

8. Davies JL, Kawaguchi Y, Bennet ST, et al. (1984) A genome-wide search for human type 1 diabetes susceptibility genes. Nature 371: 130-136

9. Field LL, Tobias R, Magnus T (1994) A locus on chromosome 15q26 (IDDM3) produces susceptibility to insulin dependent diabetes mellitus. Nature Genet 8: 189-194

10. Hanis CL, Boerwinkle E, Chakraborty K, et al. (1996) A genome-wide search for human non-insulin dependent (type 2) diabetes genes reveals a major susceptibility locus on chromosome 2. Nature Genet 13: 161-167

11. Luo-DF, Buzzetti R, Rotter JI, et al. (1996) Confirmation of three susceptibility genes to insulin-dependent diabetes mellitus: IDDM4, IDDM 5 and IDDM8. Hum Molec Genet 5: 693-698

12. Luo-DF, Bui MM, Muir A, Maclaren NK, Thomsen G, She J-X (1995) Affected sibpair mapping of a novel susceptibility gene to insulin-dependent diabetes mellitus (IDDM8) on chromosome 6q25-q27. Am J Hum Genet 51: 911-919

13. Owerbach D, Gabbay KM (1995) The HOXD8 locus (2q31) is linked to type 1 diabetes. Diabetes 44: 132-136

14. Morahan G, Huang D, Tait BD, Colman PG, Harrison LC (1996) Markers on distal chromosome 2q linked to insulindependent diabetes mellitus. Science 272: 1811-1813

15. Hashimoto L, Habita C, Beressi JP, et al. (1994) Genetic mapping of a susceptibility locus for insulin-dependent diabetes mellitus chromosome 11q. Nature 371: 161-164

16. Copeman JB, Cucca F, Hearne CM, et al. (1995) Linkage disequilibrium mapping of a type 1 diabetes susceptibility gene (IDDM7) to chromosome 2q31-q33. Nature Genetics 9: $80-85$

17. Ramachandran A, Snehalatha C, Krishnaswamy CV, Madras IDDM Registry Group (1997) Incidence of IDDM in children in urban population in Southern India. Diab Res Clin Prac (in press)

18. Gujral JS, McNally PG, Botha JL, Burden AC (1994) Childhood-onset diabetes in the white and South Asian population in Leicestershire, UK. Diabet Med 11: 570-572

19. Serjeantson SW, Ranford PR, Kirk RI, et al. (1987) HLADR and -DQ genotyping in insulin-dependent diabetes patients in South India. Dis Markers 5: 101-108

20. Kambo PK, Hitman GA, Mohan V, et al. (1989) The genetic predisposition to fibrocalculous pancreatic diabetes. Diabetologia 32: 45-51

21. Julier C, Hyer RN, Davies J, et al. (1991) Insulin-IGF2 region on chromosome $11 \mathrm{p}$ encodes a gene implicated in HLA-DR4-dependent diabetes susceptibility. Nature 354: 155-159

22. Bergholdt R, Karlsen AE, Johannesen J, et al. (1995) Characterisation of polymorphisms of an interleukin-1 receptor type 1 gene. (IL1R1) promoter region (P2) and their relation to insulin-dependent diabetes mellitus (IDDM). Cytokine 7: 727-733

23. Frankel BJ, Heldt AM, Grodsksy GM (1980) Vitamin D deficiency inhibits pancreatic secretion of insulin. Science 209: 823-825

24. Muller K, Bendtzen K (1992) Inhibition of human T lymphocyte proliferation and cytokine production by 1,25 -dihydroxyvitamin $\mathrm{D}_{3}$. Differential effects on CD45RA+ and CD45RO+ cells. Autoimmunity 14: 37-43 
25. Mathieu C, Laureys J, Sobis H, Vandeputte M, Waer M, Bouillon R (1992) 1,25-dihydroxyvitamin $\mathrm{D}_{3}$ prevents insulitis in NOD mice. Diabetes 41: 1491-1495

26. Boucher BJ, Mannan N, Noonan K, Hales CN, Evans SJW (1995) Glucose intolerance and impairment of insulin secretion in relation to vitamin D deficiency in East London Asians. Diabetologia 38: 1239-1245

27. Shan PC, Curtis D (1995) An extended transmission/disequilibrium test (TDT) for multi-allele marker loci. Am J Hum Genet 59: 323-336

28. Spielman RS, McGinnis RE, Ewens WJ (1993) Transmission test for linkage disequilibrium: the insulin gene region and insulin-dependent diabetes mellitus (IDDM). Am J Hum Genet 52: 506-516

29. Riggs BI, Nguyen TV, Melton III LJ, et al. (1995) The contribution of vitamin D receptor gene alleles to the determination of bone mineral density in normal and osteoporotic women. J Bone Miner Res 10: 991-996

30. Gyapay G, Morissette J, Vignal A, et al. (1994) The 1993 1994 genethon human genetic linkage map. Nature Genet 7: 246-339

31. Morrison NA, Qi JC, Tokita A, et al. (1994) Prediction of bone density from vitamin D receptor alleles. Nature 367: 284-287

32. Fleet JC, Harris SS, Wood RJ, Dawson-Hughes B (1995) The Bsm1 vitamin D receptor restriction fragment length polymorphism (BB) predicts low bone density in premenopausal black and white women. J Bone Miner Res 10 (6): 985-990

33. Hustmyer FG, Peacock M, Hui S, Johnston CC, Christian J (1994) Bone mineral density in relation to polymorphism at the vitamin D receptor gene locus. J Clin Invest 94: 2130 2134

34. Uitterlinden AG, Pols HAP, Burger H, et al. (1996) A large scale population-based study of the association of Vitamin D receptor gene polymorphisms with bone mineral density. J Bone Miner Res 11: 1241-1248

35. Carling T, Kindmark A, Hellman P, et al. (1995) Vitamin D receptor genotypes in primary hyperparathyroidism. Nat Med 12: 1309-1311

36. Farrow S (1994) Alleleic variation and the vitamin D receptor. Lancet 343: 1242

37. Mahtani MM, Widen E, Jehto M, et al. (1996) Mapping of a gene for type 2 diabetes associated with an insulin secretion defect by a genome scan in Finnish families. Nature Genet 14: 90-94

38. Vaxillaire M, Boccio V, Philippi A, et al. (1995) A gene for maturity onset diabetes of the young (MODY) maps to chromosome 12q. Nature Genet 9: 418-423

39. Yamagata K, Oda N, Kaisaki P, et al. (1996) Mutations in the hepatocyte nuclear factor- $1 \alpha$ gene in maturity-onset diabetes of the young (MODY3). Nature 384: 455-458 